\title{
LADDERTRON DEVELOPMENTS
}

\author{
T. W. AITKEN and J. M. LEESE \\ Daresbury Laboratory, Science Research Council, Daresbury, \\ Warrington WA4 4AD, England
}

\begin{abstract}
Résumé. - Le développement récent des laddertrons à Daresbury est décrit. La dernière version peut transporter un courant de charge allant jusqu'à $500 \mu \mathrm{A}$ à une vitesse de $12 \mathrm{~m} / \mathrm{s}$ dans des gradients allant jusqu'à $3,3 \mathrm{MV} / \mathrm{m}$. La plus longue chaîne verticale, qui a déjà fonctionné mesure $20 \mathrm{~m}$ entre les poulies et les résultats des essais sont décrits.
\end{abstract}

\begin{abstract}
Recent developments in laddertrons at Daresbury are described. The latest version can transport up to $500 \mu \mathrm{A}$ of charging current at a speed of $12 \mathrm{~m} / \mathrm{s}$ in gradients as high as $3.3 \mathrm{MV} / \mathrm{m}$. The longest vertical chain which has so far been run measures $20 \mathrm{~m}$ between pulleys and the results of these tests are described.
\end{abstract}

1. The Mark I Laddertron. - Since the first International Conference on the Technology of Electrostatic Accelerators at Daresbury in 1973 considerable progress has been made in laddertron design. At that Conference the $11 \mathrm{~m}$ long Mark I chain designed at Daresbury which had just been constructed was demonstrated [1]. This chain was subsequently installed in the pilot test machine and a comprehensive programme of measurements was carried out on it. As well as determining accurately its current carrying capability, voltage hold-off and self charge extremely detailed measurements were made of its windage using different lengths of chain [2]. The development of special EHT supplies, pulley wheels and electrodes was also carried out. It was shown that more than $500 \mu \mathrm{A}$ of charge could be transported at voltage gradients in excess of that required for the tandem. The self charge was under $1 \mu \mathrm{A}$ even at full $\mathrm{SF}_{6}$ pressure and the windage presented no problem. Some initial trouble arising from the use of glass filled nylon for the links was overcome by changing to monocast nylon.

These detailed tests showed up two areas which could be improved. One was to simplify the construction from the unit shown in figure 1 consisting of many pieces to one in which the rung was an integral unit. The other was to increase the voltage hold-off so that it was much higher than that of the column. The Mark I chain had a similar hold-off voltage to the column so that if the latter was taken to extremely high gradients there was a possibility that small electrical disturbances in the chain could cause the chain to break down.

2. The Mark II Chain. - A new laddertron chain, called the Mark II, was built to incorporate these additional features. Information obtained from the

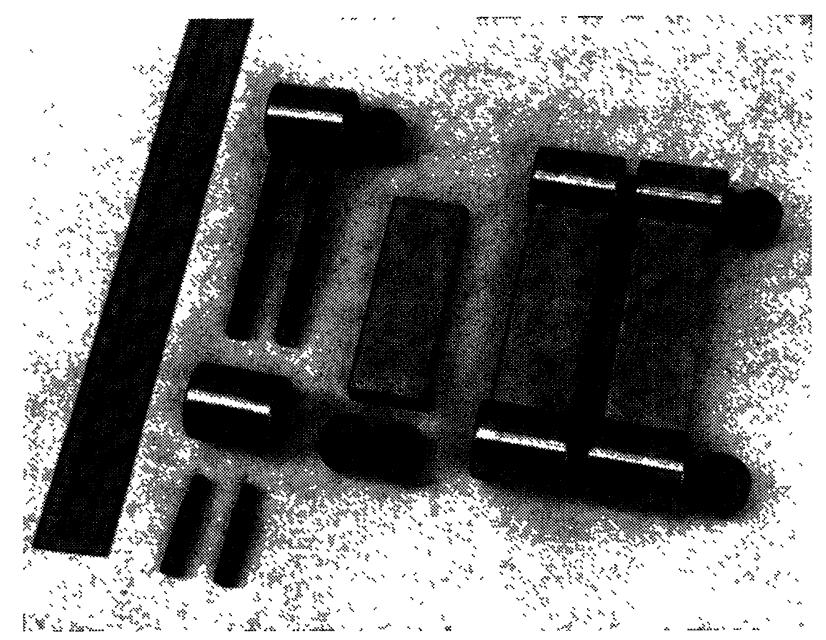

FIG. 1. - Construction of the Mark I laddertron chain.

tests of the Mark I system, particularly the windage measurements, helped greatly in defining the design requirements for this chain [3]. It allowed the gradient to go up to about $20 \%$ higher than the maximum stack gradient of $3.3 \mathrm{MV} / \mathrm{m}$, and gave even better mechanical performance due to its rigid construction. Rather than machining the components from solid, they were cast in stainless steel and brazed together. This proved to be extremely difficult technically and it was difficult using the techniques available to make the chain as light as desired. Rather than delay the programme this chain was built so that high voltage tests could go ahead while further development was carried out to try to reduce the weight.

3. The Mark III Chain. - It has now been possible to produce Mark II rungs which are much lighter, without altering the electrical design in any way. For convenience this is called the Mark III chain. It has a 
linear density identical to that of the Mark I i.e. $6.4 \mathrm{~kg} / \mathrm{m}$. The construction is shown in figure 2 . The reduction in weight has been achieved by machining down the cylindrical end castings and by using a hollow rung.

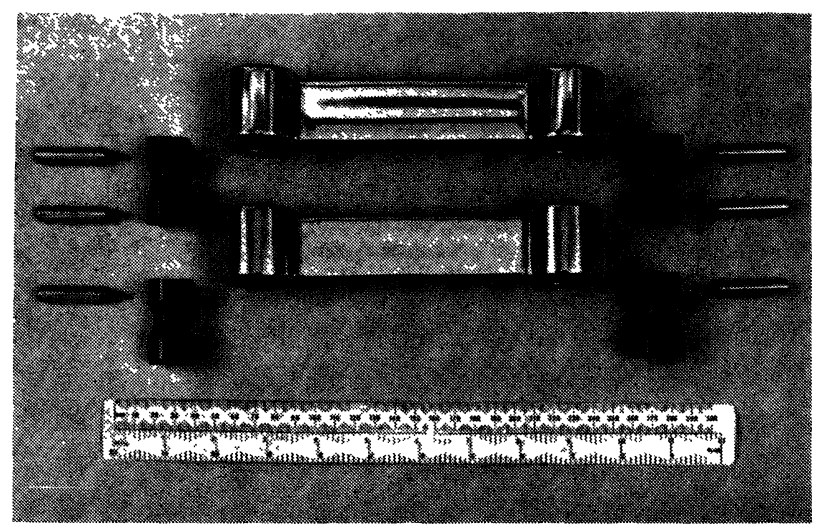

FIG. 2. - Construction of the Mark III laddertron chain.

4. Performance of the Mark II/Mark III Systems. - The Mark II system which has been running in the pilot machine for 17 months is a beautiful system to work with. It has required no maintenance over this period and can simply be switched on and run, without any conditioning or drying, straight up to full gradient. The use of individual power supplies on all four electrodes, two for inductors and two for suppressors, gives a completely linear and reproducible behaviour with the minimum of pulley wear due to spark erosion. The rigidity of the chain structure has resulted in the complete absence of mechanical oscillations, any slight movement of the chain being repetitive at the rotation frequency and purely due to slight differences in the lengths of the two sides. Capacitance probe measurements of the terminal voltage indicate a stability of 1 in $10^{4}$ with the main component at rotation frequency. It has been shown that this can be reduced if necessary by modulating the charging voltages. Experiments on the effect of downcharge current modulation on the terminal voltage have been carried out over a wide range of frequencies and these fit a simple theoretical model of the machine extremely well. These measurements have been published [4].

The latest development has been the mechanical testing of a $41.5 \mathrm{~m}$ long Mark III chain in a vertical test rig. This is the chain which will be installed in the $30 \mathrm{MV}$ tandem and it was about 4 times longer than any which had been run before.

Figure 3 shows the upper system or idler unit over which the chain runs. To equalise the load on each of the pulleys it has articulated members which allow them to move parallel to one another. The unit is supported on a number of anti-vibration mounts to isolate it from the stack. Figure 4 shows the bottom drive unit with the entire system mounted on two vertical runners to allow it to follow variations in the

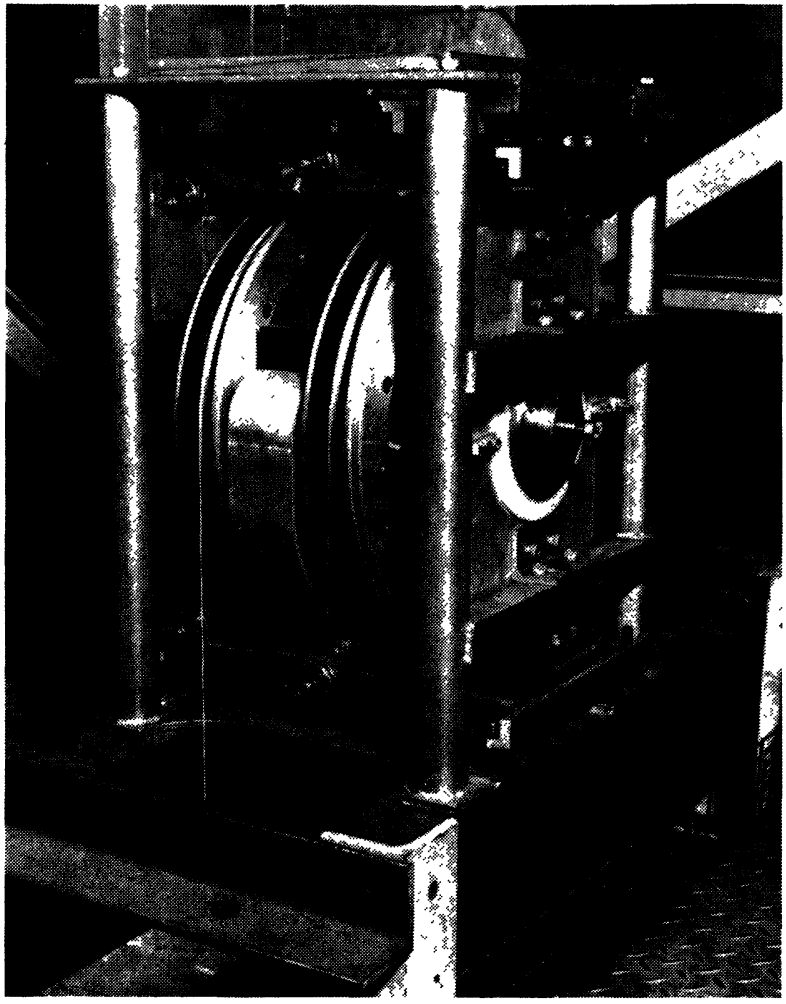

FIG. 3. - Idler unit for $41 \mathrm{~m}$ long chain.

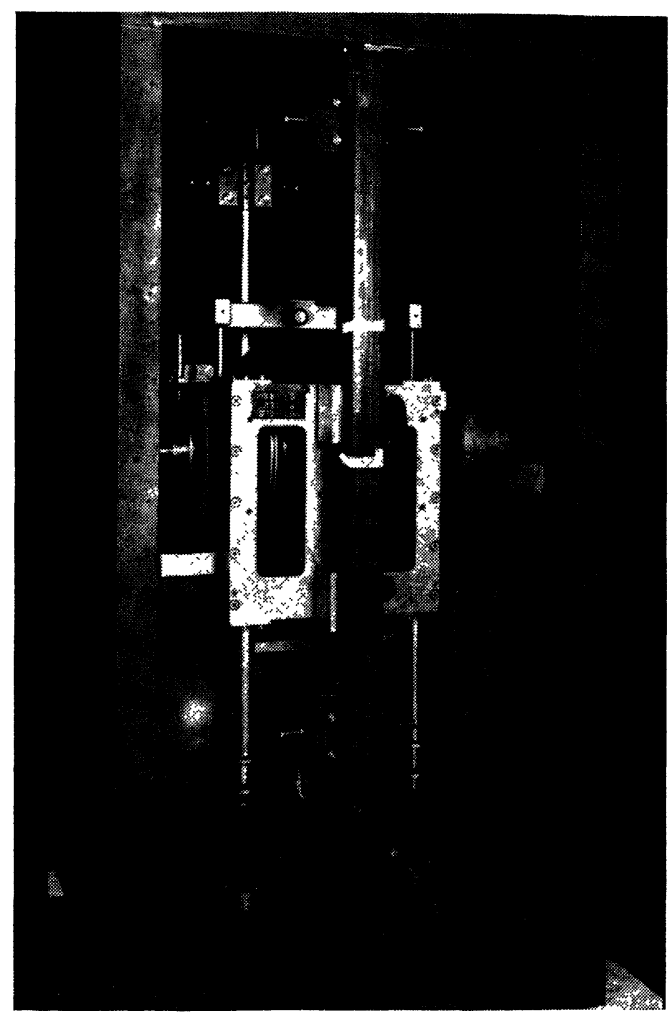

FIG. 4. - Drive unit for $41 \mathrm{~m}$ long chain.

length of the chain. The chain was completely free between the top and bottom pulleys, i.e. there were no damping pulleys. There were, however, nylon skates at the midpoint and microswitch sensors a few centimetres away from the chain as safety precautions to 
cut the drive should any oscillations have built up. These were never required.

The system was run at all speeds up to $15 \mathrm{~m} / \mathrm{s}$ with very encouraging results. The worst movement of the chain at the mid position, was $\pm 1 \mathrm{~cm}$ and this was repetitive at the rotation frequency. The elasticity of the chain and stretch as a function of speed agreed with the predictions. Attempts to induce oscillations in the chain during running were made but these could not be built up even when the speed was modulated at the fundamental frequency $(0.25 \mathrm{~Hz})$. In compressed
$\mathrm{SF}_{6}$, which has a much higher density than air, damping forces will be larger and hence stability should be even more certain. In view of this it is not intended to provide idler wheels in the $30 \mathrm{MV}$ machine unless this proves unavoidable. Safety features will however be incorporated of a similar type to that described above.

This chain is at present being polished and prepared for installation in the $30 \mathrm{MV}$ tandem. It will undergo electrical tests as a working system in the pilot machine in four individual sections before final installation.

\section{References}

[1] Aitken T. W. and Charlesworth T. R., Daresbury Laboratory Technical Memorandum DL/NSF/TM13 (1975).

[2] Aitken T. W., Daresbury Laboratory Technical Memorandum DL/NSF/TM14 (1975).

[3] Aitken T. W., Daresbury Laboratory Technical Memorandum DL/NSF/TM15 (1975).

[4] Aitken T. W., Nucl. Instrum. Methods 129 (1975) 341. 